\title{
Optimization of molecular detection of GD2 synthase mRNA in retinoblastoma
}

\author{
VIVIANA E. LAURENT ${ }^{1,2}$, LAURA L. OTERO ${ }^{1}$, VALERIA VAZQUEZ ${ }^{1}$, SANDRA CAMARERO ${ }^{3}$, \\ MARIANO R. GABRI ${ }^{1}$, MARÍA LABRAGA ${ }^{3}$, MARÍA T.G. DE DÁVILA ${ }^{3}$, \\ GUILLERMO L. CHANTADA ${ }^{2}$ and DANIEL F. ALONSO ${ }^{1}$ \\ ${ }^{1}$ Laboratory of Molecular Oncology, Quilmes National University; Departments of ${ }^{2}$ Hemato-oncology, and \\ ${ }^{3}$ Pathology and Tumor Bank, Pediatric Hospital Professor Dr Juan P. Garrahan, Buenos Aires, Argentina
}

Received November 17, 2009; Accepted January 4, 2010

DOI: $10.3892 / \mathrm{mmr} 00000248$

\begin{abstract}
Extraocular dissemination is the main cause of death in patients with retinoblastoma $(\mathrm{RB})$ in developing countries, and there are few molecular markers that are useful for the evaluation of minimal disseminated disease. The GD2 ganglioside is known to be expressed by RB cells that metastasize in bone marrow, and the activity of the enzyme responsible for its synthesis, GD2 synthase, can be detected in neuroblastoma, which shares many phenotypic features with RB. The purpose of the present study was to optimize the detection of GD2 synthase expression by reverse transcription-polymerase chain reaction (RT-PCR) followed by nested-PCR in human RB cell lines and patient samples. The optimization strategy was carried out using the RB cell lines Y79 and WERI-Rb1 and specific primers designed for the human sequence of GD2 synthase mRNA. We detected GD2 synthase expression with at least 200 and $40 \mathrm{pg}$ of total RNA extracted from cultured RB cells using a first round of RT-PCR amplification or a second round of nested-PCR, respectively. We also confirmed the expression of GD2 synthase by RT-PCR and immunohistochemical detection of the ganglioside in human RB tumors xenotransplanted in nude mice. Using tumor bank specimens from eight RB patients, we were able to demonstrate the presence of GD2 synthase mRNA in blood and cerebrospinal fluid samples in cases of extraocular dissemination of the tumor. The sequence was not detected in samples derived from children with low-risk disease or healthy adult volunteers. Hence, GD2 synthase mRNA detection through an optimized nested RT-PCR assay is a promising tool for the assessment of minimal disseminated disease in enucleated patients.
\end{abstract}

Correspondence to: Dr Daniel Alonso, Laboratorio de Oncología Molecular, Departamento de Ciencia y Tecnología, Universidad Nacional de Quilmes, R. Sáenz Peña 352, Bernal B1876BXD, Buenos Aires, Argentina

E-mail: dfalonso@unq.edu.ar

Key words: GD2 synthase, reverse transcription-polymerase chain reaction, retinoblastoma, minimal disseminated disease, high-risk patient

\section{Introduction}

Retinoblastoma (RB) is the most common eye cancer in children, affecting 1 in 15,000-20,000 births (1) and accounting for $4 \%$ of all pediatric malignancies (2). It is caused by the accumulation of mutations in both alleles of the RB1 gene, the first cancer gene identified and cloned in 1986 (3). When it disseminates outside the eye, it is associated with a dismal patient prognosis. In developing countries with poor education, socioeconomic conditions and health care systems, delayed diagnosis and suboptimal care constitute the common scenario $(4,5)$. Therefore, while salvage has become a priority in developed countries, this is currently not the case in less developed ones, where death from RB remains a major issue (6-9). In Argentina and other countries with a similar degree of socioeconomic development, there is a greater than $80 \%$ chance of survival, but microscopical invasion of the ocular coats, requiring more intensive treatment, is still common. Some of these patients die due to extraocular disease after undergoing enucleation when adequate post-operative treatment is not provided (5). The risk of extraocular relapse is currently estimated by assessing the invasion of ocular coats such as the optic nerve, choroid or sclera, with adjuvant therapy administered to patients based upon this information. However, there is no consensus regarding the value of each of these prognostic factors $(10,11)$.

This estimation, based upon histopathological risk factors, has a limited sensitivity for identifying patients at risk due to minimal disseminated disease (MDD). Thus, some patients needing adjuvant therapy may be overlooked while, conversely, some identified as being at a higher risk by histopathology may not need adjuvant therapy, and are therefore unnecessarily exposed to the adverse effects of high-dose chemotherapy (12-14). Adjuvant therapy usually requires the use of high doses of chemotherapy, including drugs with good penetration into the central nervous system $(15,16)$, where recurrences are more likely.

Since Smith et al first reported the use of the reverse transcription-polymerase chain reaction (RT-PCR) methodology for the amplification of tyrosinase transcripts to detect circulating melanoma cells in peripheral blood samples in 1991 (17), molecular detection of MDD utilizing specific target sequences has been proposed for several types of cancer (18) due to its high 
specificity and sensitivity. However, in RB a major obstacle for MDD detection is the lack of specific tumor markers. Certain gangliosides are the most frequently used molecular markers for such a purpose in other pediatric malignancies that share a similar antigenic profile with $\mathrm{RB}$, such as neuroblastoma (19). Gangliosides are involved in normal biological functions including cell adhesion, cell-cell interactions and proliferation (20). Specific alterations in the expression of gangliosides after neoplastic transformation, which are likely involved in the metastatic phenotype of malignant cells $(21,22)$, have been found, particularly in tumors of neural crest-derived tissues (23).

One of the most extensively studied molecular markers for the detection of MDD in neuroblastoma is the transcript of the $\beta 1,4-\mathrm{N}$-acetylgalactosaminyltransferase (GD2 synthase) gene $(19,24)$. GD2 synthase is the key enzyme required for the synthesis of the GD2 ganglioside (25), and is commonly expressed in normal tissues such as the brain and in several tumor types, as previously mentioned (23).

To date, molecular markers for RB that can be used for the determination of MDD have received little attention in the scientific literature, probably since extraocular dissemination is uncommon in more developed countries. The finding of such a molecular marker for MDD detection would not only allow for more appropriate therapeutic decision making before metastasis or a potential recurrence takes place, but would also allow for the monitoring of the outcome of patients during treatment. The possibility of identifying a high-risk subgroup of patients through the detection of this type of marker may result in the prevention of metastasis by the selection of a more personalized adjuvant therapy. As GD2 synthase has proven to be a useful molecular marker in neuroblastoma, and given the fact that the GD2 ganglioside was found to be shed from human RB tumors (26) and was found in the bone marrow of RB patients (27), we suggest that it may be a good candidate for MDD detection in RB.

Based on these findings, our aim was to study the expression of GD2 at the immunohistochemical level and to detect the GD2 synthase transcript in human RB cell lines and patient samples by means of an optimized nested RT-PCR technique. We also pursued the design of novel high-affinity primers for this sequence.

\section{Materials and methods}

Cell lines. The human RB cell lines Y79 and WERI-Rb1 were cultured in suspension in RPMI-1640 medium (Gibco BRL) with 20 or $10 \%$ heat-inactivated fetal bovine serum (PAA Laboratories $\mathrm{GmbH}$ ), respectively. Cultures were maintained at $37^{\circ} \mathrm{C}$ in $5 \%$ carbon dioxide and at the appropriate conditions of humidity, with change of the culture medium once or twice weekly. The culture medium was supplemented (per liter) with $2.5 \mathrm{~g}$ glucose, $2.38 \mathrm{~g}$ HEPES, $1 \mathrm{mM}$ sodium pyruvate, $1.5 \mathrm{~g}$ sodium bicarbonate and $2 \mathrm{ml}$ gentamycin $(80 \mathrm{mg} / \mathrm{ml})$ as specified by the supplier (ATCC). RNA from other human tumor cell lines (MCF7 breast, HeLa cervical and H125 lung human carcinomas) had previously been extracted and stored at our laboratory.

Tumor growth in nude mice. Specific pathogen-free athymic female nude (nu/nu) Balb/c mice were purchased from the
Animal Facility of UNLP (Argentina) and maintained in sterile isolated conditions. Water and food was given ad libitum. All animal protocols were supervised and managed by qualified trained personnel according to the international guidelines for animal care.

Y79 cells were harvested by centrifugation, washed twice and resuspended in RPMI-1640 medium or in $10 \mathrm{mg} / \mathrm{ml}$ cold liquid Matrigel (BD Biosciences) in a final volume of $250 \mu \mathrm{l}$ at a concentration of $1 \times 10^{6}$ cells/mouse. Tumor cells were immediately inoculated in the subcutis of the flank of nude mice with either culture media or Matrigel (28). Animals were monitored twice a week for 4 weeks until tumors reached a mean diameter of $\sim 10 \mathrm{~mm}$. Tumor tissue from growing tumors was either fixed in $10 \%$ buffered formalin for immunohistochemical studies or rapidly frozen at $-70^{\circ} \mathrm{C}$ for mRNA isolation.

Immunohistochemical detection of ganglioside GD2. Formalin-fixed paraffin-embedded tissue blocks of RB tumors generated in nude mice were sectioned $(3 \mu \mathrm{m})$, mounted on silanized slides, deparaffinized in xylene, blocked in $3 \% \mathrm{H}_{2} \mathrm{O}_{2}$ and processed for antigen retrieval in pre-heated sodium-citrate buffer ( $\mathrm{pH}$ 6.0). The murine anti-GD2 monoclonal antibody 3F8 was provided by Dr Nai-Kong V. Cheung (Memorial Sloan-Kettering, NY, USA). Samples were incubated overnight with the antibody (1:50) at $4^{\circ} \mathrm{C}$ in a moist chamber. After washing with Tris-buffer ( $\mathrm{pH} 7.3)$, a peroxidase-labeled polymer conjugated to secondary anti-mouse antibodies (Dako EnVision Detection System) was applied, and samples were further incubated for $30 \mathrm{~min}$ at room temperature and developed with diaminobenzidine as the chromogen. Sections were counterstained with Mayer's hematoxylin, then dehydrated, cleared and mounted.

Sample collection and processing. Peripheral blood (PB), cerebrospinal fluid (CSF) and tumor samples from patients $<5$ years of age who had undergone enucleation were obtained from the Tumor Bank of the Periatric Hospital Professor Dr Juan P. Garrahan (Buenos Aires, Argentina) for use in this study. Written informed consent was obtained from all patient guardians, and ethical approval was obtained from the Institutional Review Board of the hospital. The patient samples and PB samples from healthy adult volunteer donors were processed for GD2 synthase mRNA detection. Each sample was stored in a 1:1.5 ratio of sample:guanidinium thiocyanate (GTC) buffer. The buffer contained $6 \mathrm{M} \mathrm{GTC} \mathrm{(Promega),}$ $0.0375 \mathrm{M}$ sodium citrate and $0.75 \% \mathrm{~N}$-lauroylsarcosine. After mixing, the sample/GTC mixtures were stored immediately at $-70^{\circ} \mathrm{C}$ until use. In order to achieve a final GTC concentration of $4 \mathrm{M}$ (29), $3 \mathrm{ml}$ of PB and CSF extracted from the patients was collected directly in $4.5 \mathrm{ml}$ of $6 \mathrm{M} \mathrm{GTC}$ buffer. Due to the small size, tumor samples were collected in $4 \mathrm{M}$ GTC buffer, on the assumption that the amount of samples would not affect the buffer concentration.

RNA extraction. RNA extraction from cell lines and patient samples was conducted at $4^{\circ} \mathrm{C}$ based on TRIzol extraction methodology (TRIzol LS Reagent; Invitrogen) according to the manufacturer's instructions. RNA pellets were resuspended in a 30- $\mu$ l final volume of DEPC-treated water and stored at 
Table I. Primers for amplification of GD2 synthase and GAPDH mRNA sequences.

\begin{tabular}{llll}
\hline mRNA & Forward primer & Reverse primer & Product size (bp) \\
\hline GD2 & & & 347 \\
RT-PCR & 5'-TCGGCTACGGCTCTCATCACCAG-3' & 5'-CTGAGCGTGGAGCCCGGCG-3' & 180 \\
Nested-PCR & 5'-GAACCTGGCCGTGTCTCAAGTAAC-3' & 5'-CACCACTTATCGGCAGCTGCT-3' \\
GAPDH & & & 457 \\
RT-PCR & 5'-GGGGAGCCAAAAGGGTCATCATCT-3' & 5'-GACGCCTGCTTCACCACCTTCTTG-3' & 450 \\
\hline
\end{tabular}

$-70^{\circ} \mathrm{C}$ until use. In the case of small samples such as tumor fragments or CSF, we used ultrapure glycogen (Invitrogen) as a carrier to optimize the extraction. RNA was first quantified spectrophotometrically, and its integrity was assessed electrophoretically after using the obtained RNA as a template for glyceraldehyde 3-phosphate dehydrogenase (GAPDH) mRNA amplification.

Primer design. The design of highly specific primers for the human GD2 synthase mRNA sequence (GenBank accession no. NM_001478) was carried out with PrimerSelect ${ }^{\mathrm{TM}}$ 5.05 software (DNAstar Inc.), with default settings applied. The best score, the lower difference in melting temperature between each pair of primers $\left(<1^{\circ} \mathrm{C}\right)$, and the best sequential and structural features to prevent intramolecular or intermolecular secondary structures were considered. In addition, an inter-exonic design was employed, thereby allowing for the distinction between the amplification of contaminating genomic DNA present in the sample from those amplified from the transcripts. Primer details are presented in Table I.

RT-PCR optimization. RNA samples were analyzed by a twostep RT-PCR assay using specific primers for a 347-bp GD2 synthase mRNA fragment, as well as specific primers for a 457-bp fragment from the housekeeping gene GAPDH as a loading and integrity control. The first step of cDNA synthesis was carried out in a final volume of $50 \mu \mathrm{l}$ using the Illustra ${ }^{\mathrm{TM}}$ Ready-To-Go ${ }^{\mathrm{TM}}$ RT-PCR Bead kit (GE Healthcare) and $1 \mu \mathrm{l}$ of random hexamers $\mathrm{pd}(\mathrm{N})_{6}(12 \mathrm{pmol} / \mu \mathrm{l})$ at $43^{\circ} \mathrm{C}$. In the second step, $1 \mu \mathrm{l}$ of the forward and reverse primers was added. To optimize the RT-PCR, we evaluated several parameters that are known to influence the outcome of this type of assay. After optimization, a typical 50- $\mu 1$ reaction included $2 \mu \mathrm{l}$ RNAse Out (80 U; Invitrogen), $2 \mu \mathrm{Mg}^{2+}$ (25 mM; Promega) and $1 \mu \mathrm{l}$ DTT (1 mM; Invitrogen). Amplification was carried out for 60 cycles with a $63.7^{\circ} \mathrm{C}$ annealing temperature. We also tested different types of first-strand primers during the reverse transcription stage, such as $\operatorname{pd}(\mathrm{T})_{12-18}(0.5 \mu \mathrm{g} / \mu \mathrm{l})$, the reverse PCR primer, and random hexamers $\operatorname{pd}(\mathrm{N})_{6}$, the latter being the best option. The optimal final concentration of primers used was $0.24 \mathrm{pmol} / \mu \mathrm{l}$. A final volume of $50 \mu \mathrm{l}$ was completed with DEPC-treated water. We used 5 ng RNA from the Y79 human RB cell line as a template for each optimization round. PCR products were analyzed by electrophoresis on $2 \%$ agarose gels followed by ethidium bromide staining.

RT-PCR and nested-PCR assay. For each RT-PCR reaction, both a loading and integrity control (GAPDH) and a negative control (without template) were used, as well as a positive GD2 amplification control (5 ng of total RNA from Y79). For patient samples, $25 \mu \mathrm{l}$ total RNA was employed as a template for the GD2 analysis (regardless of the RNA concentration obtained), and $4 \mu$ l total RNA was used for GAPDH amplification. Second round (nested-PCR) reactions consisted of a $1-\mu 1$ aliquot of the first round reaction mix as a template, $1 \mu \mathrm{l}(12 \mathrm{pmol} / \mu \mathrm{l})$ of each specific nested primer and $27 \mu \mathrm{l}$ Platinum ${ }^{\circledR}$ PCR Supermix (Invitrogen) in a $30-\mu 1$ final reaction volume. Finally, $45 \mu \mathrm{l}$ of the first round reaction volume and $30 \mu \mathrm{l}$ of the second were subjected to electrophoresis in the agarose gels.

The cycling profile for the first round of amplification was carried out as follows: reverse transcription, $1 \mathrm{~h}$ at $43^{\circ} \mathrm{C}$; initial denaturation, $5 \mathrm{~min}$ at $95^{\circ} \mathrm{C}$; amplification (60 cycles), $1 \mathrm{~min}$ at $95^{\circ} \mathrm{C}, 1 \mathrm{~min}$ at $63.7^{\circ} \mathrm{C}$ and $30 \mathrm{sec}$ at $72^{\circ} \mathrm{C}$; final extension, $10 \mathrm{~min}$ at $72^{\circ} \mathrm{C}$. For the second round, cycling consisted of: initial denaturation, $1 \mathrm{~min}$ at $95^{\circ} \mathrm{C}$; amplification (30 cycles), $30 \mathrm{sec}$ at $95^{\circ} \mathrm{C}, 30 \mathrm{sec}$ at $60.2^{\circ} \mathrm{C}$ and $30 \mathrm{sec}$ at $72^{\circ} \mathrm{C}$; final extension, $5 \mathrm{~min}$ at $72^{\circ} \mathrm{C}$.

\section{Results}

In order to determine whether the putative marker, GD2 synthase, was present in an in vivo context, we first tested the expression of the GD2 synthase product, the GD2 ganglioside, using a xenograft model by means of an immunohistochemical method as indirect evidence of enzyme expression in tumors. For this purpose, Y79 cells were injected into the flank of nude mice with culture medium or Matrigel to allow for tumor development. Animals developed subcutaneous RB tumors with a latency of 12 or 4 days, and a volume of $\sim 250$ or $1,000 \mathrm{~mm}^{3}$ at 25 days after inoculation, for medium or Matrigel injection, respectively. Evaluation with the specific anti-GD2 antibody 3F8 confirmed the abundant expression of the ganglioside in the cell membranes and cytoplasm of the Y79 tumor cells (Fig. 1A). Other portions of the same tumors were subjected to RNA extraction and subsequently analyzed by an appropriately optimized RT-PCR assay. The first round of amplification detected an almost identical GD2 synthase mRNA level as in the positive control in the xenograft tumors generated either with or without Matrigel (Fig. 1B).

After achieving an easily visible band of the expected size for the target amplicon in 2\% agarose gels, we accomplished the optimization process of the RT-PCR assay for the GD2 synthase mRNA (Materials and methods). The sensitivity and specificity of the optimized assay was determined by analyzing serially reduced amounts of template, starting from 


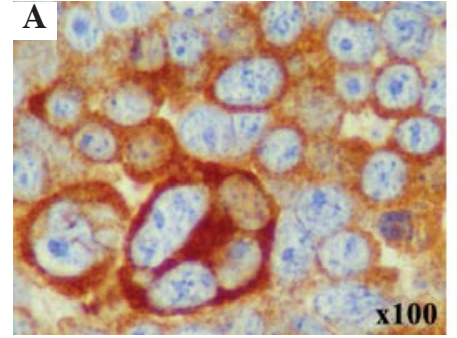

$\mathbf{B}$

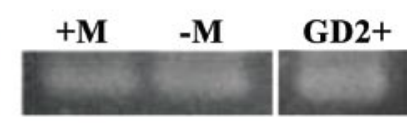

RT-PCR

$\mathbf{A}$

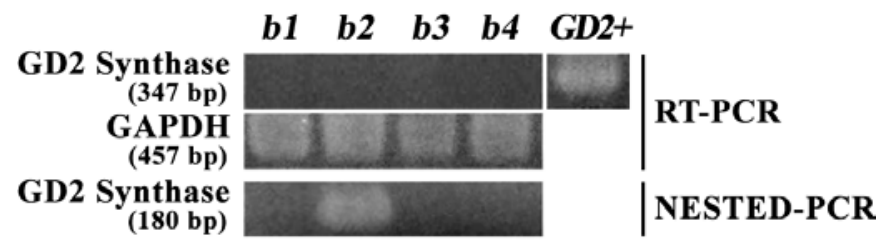

B

Figure 1. (A) Immunohistochemical detection of GD2 ganglioside in paraffinembedded material from a Y79 xenograft tumor generated with Matrigel in the subcutis of nude mice. (B) GD2 synthase expression tested by RT-PCR in human Y79 retinoblastoma tumors generated in nude mice. Lane +M, RNA extracted from a Y79 tumor generated by co-injection with Matrigel; lane -M, RNA extracted from a Y79 tumor generated by co-injection with culture medium alone without Matrigel; lane GD2+, positive control (5 ng of total RNA from Y79 cultured cells).

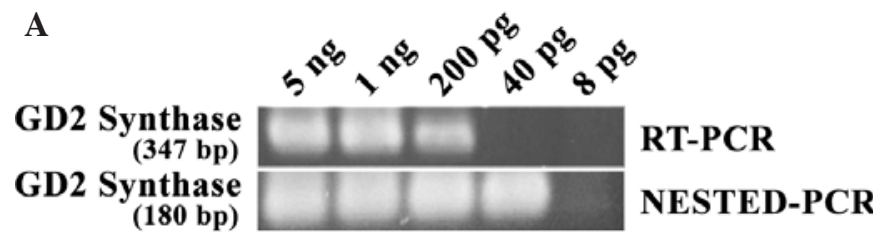

B

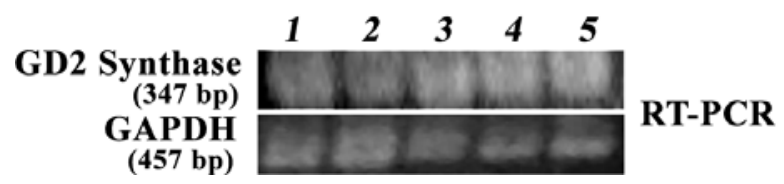

Figure 2. In vitro sensitivity and specificity of the RT-PCR assay. (A) Detection of human GD2 synthase mRNA in a serial 1:5 dilution of total RNA obtained from the Y79 retinoblastoma cell line. (B) Detection of the target sequence in human carcinoma and retinoblastoma cell lines using $5 \mathrm{ng}$ of total RNA as a template. Lane 1, WERI-Rb1 retinoblastoma; lane 2, MCF7 breast carcinoma; lane 3, HeLa cervical carcinoma; lane 4, H125 lung carcinoma; lane 5, Y79 retinoblastoma cell lines. RT-PCR products were analyzed by $2 \%$ agarose gel electrophoresis and dyed with ethidium bromide (experimental details in Materials and methods).

5 ng of total RNA obtained from human RB cells as well as from other tumor cell lines. As shown in Fig. 2A, we detected the GD2 synthase transcript when using at least $200 \mathrm{pg}$ of total RNA from the Y79 cells in the first amplification reaction. This sensitivity was further improved by nested amplification, in which the GD2 synthase transcript was detected when using $40 \mathrm{pg}$ total RNA. In both rounds, the products obtained showed their predicted sizes (347 bp in the first and $180 \mathrm{bp}$ in the second round of amplification). Similar results were obtained with the WERI-Rb1 cell line. Using the same amount of total RNA (5 ng), we also observed GD2 synthase mRNA amplification in human carcinoma cell lines (Fig. 2B). In all cases, RNA integrity was confirmed by RT-PCR using specific primers for GAPDH mRNA.

We subsequently tested eight tumor bank samples from different RB patients in order to preliminarily examine the potential clinical value of the present RT-PCR assay in detecting disseminated tumor cells. Six of these patients had no histopathology risk factors on examination, one patient had stage 2 disease due to tumor invasion of the optic nerve at

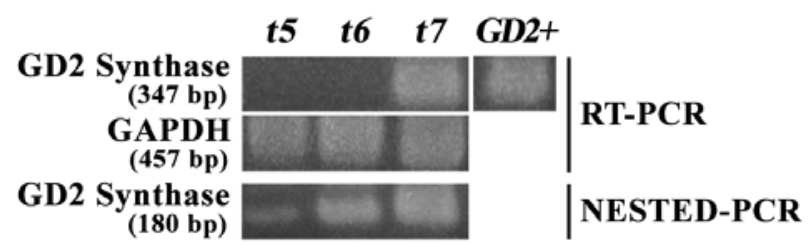

C

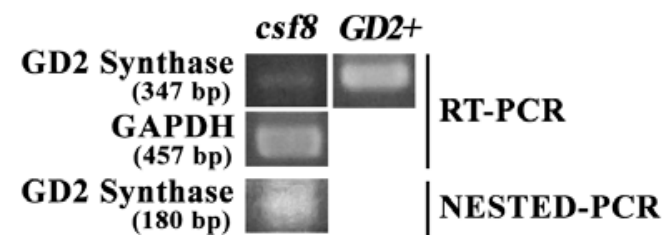

Figure 3. Molecular detection of GD2 synthase mRNA by RT-PCR and nested-PCR in samples from RB patients. A total of eight samples from eight different cases were available for analysis. (A) Blood samples, lanes b1-b4. (B) Tumor samples, lanes t5-t7. (C) CSF sample, lane csf8. In all cases, the GAPDH sequence was used as a control for the load and integrity of the RNA. GD2+, positive control (5 ng of total RNA from Y79 cultured cells) (experimental details in Materials and methods).

the resection margin as well as microscopical choroid invasion, while the remaining patient had stage 4a disease due to bone marrow metastasis (30). In this patient, the optic nerve stump was also involved. The patient with stage 2 disease, who was hence at high risk of relapse, presented no target amplification in PB in the first round of RT-PCR. However, when nested-PCR was performed, a clear GD2 synthase band was detected (Fig. 3A, lane b2). He was treated with adjuvant systemic chemotherapy and orbital irradiation according to the institutional protocol (31), and has been in complete remission for 25 months. The patient with stage $4 \mathrm{a}$ disease had GD2-positive cells by immunocytology in the bone marrow (data not shown) and showed a faint band corresponding to GD2 synthase mRNA visible in the first round of RT-PCR amplification in the CSF sample at diagnosis and a clear band in the nested-PCR (Fig. 3C, lane csf8). Neither cytological examination of the CSF centrifugate nor immunocytology for GD2 detected tumor cells. No PB sample was available at the tumor bank for this patient. The patient was treated with intensive chemotherapy including autologous stem cell rescue, but relapsed in the CSF 11 months post-transplantion and succumbed to resistant disease. By contrast, none of the other PB samples, which were derived from patients who did not present histological high-risk features, were positive for GD2 synthase after RT-PCR or nested-PCR (Fig. 3A).

We also analyzed the expression of GD2 synthase in human tumor samples from another three patients from the tumor bank in order to verify whether GD2 synthase was expressed as in the cell lines. As shown in Fig. 3B, only one sample was 
b9 b10 b11 b12 b13 b14 b15 b16 GD2+

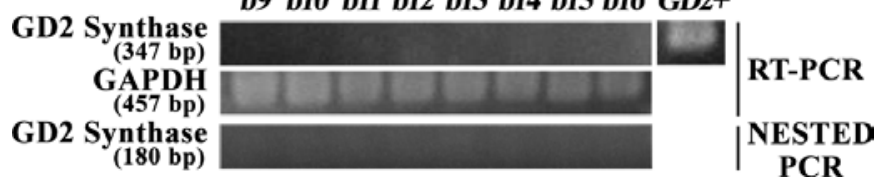

Figure 4. GD2 synthase expression tested by RT-PCR and nested-PCR in peripheral blood samples from healthy adult volunteers. Blood samples were designated b9-b16. In all cases, the GAPDH sequence was used as a control for the load and integrity of the RNA. GD2+, positive control (5 ng of total RNA from Y79 cultured cells) (experimental details in Materials and methods).

positive in the first round of amplification (lane t7). Using a second round of amplification, all tumor samples were positive for GD2 synthase, as expected (Fig. 3B).

In addition, we checked target mRNA expression in $\mathrm{PB}$ samples obtained from eight healthy adult donors. All samples were negative for GD2 synthase mRNA expression after either the first or second round of amplification (Fig. 4).

\section{Discussion}

In the present study, we detected for the first time the expression of GD2 synthase mRNA in RB cell lines and tumor samples from RB patients. The presence of GD2 synthase and the GD2 ganglioside in RB tumors was also confirmed by RT-PCR and immunohistochemical assays using a xenograft model. Despite the fact that one of the three tumor samples was positive in the first round of amplification, the other two required a second round for the detection of GD2 synthase mRNA. This may have been due to a poor harvest of viable cells during tumor sampling. In this regard, the relationship between the mRNA level of glycosyltransferases and the presence of their products was established elsewhere (21) Therefore, as it is now routinely used for neuroblastoma, GD2 synthase may be a suitable molecular marker for the detection of MDD in RB.

To the best of our knowledge, there have been few previous reports concerning the use of molecular markers for minimal residual disease (MRD) assessment by RT-PCR in RB. Instead, other traditional techniques such as cytometric methods, standard light microscopy (32), immunocytochemistry/ cytology and fluorescence-activated flow cytometry (27) have been used for MRD analysis in RB.

Yamane et al (33) serially assessed, using RT-PCR, the expression of the neuroendocrine protein gene product PGP9.5 in PB mononuclear cells, bone marrow and mobilized PB stem cells from a single RB patient with metastatic disease. The aim was to use PGP9.5 expression as a predictable marker for detecting MRD after intensive therapy and for evaluating therapeutic effects. However, the specificity of PGP9.5 gene transcripts in the detection of micrometastasis in blood and bone marrow in neuroblastoma was not convincing, since the marker was also found in control samples in another investigation (34).

More recently, Yamashita et al (35) presented a case report of a patient with disseminated RB and evaluated three different gene sequences: cone $\alpha$-subunit of cGMP phosphodiesterase, rod $\beta$ '-subunit of cGMP phosphodiesterase $(\operatorname{rod} \beta$-PDE) and interphosphoreceptor retinoid-binding protein (IRBP). The authors concluded that molecular detection of IRBP is useful in cases of disseminated RB to ascertain the safety of stem cell transplantation, and that both IRBP and rod $\beta$-PDE are more suitable for monitoring the effectiveness of chemotherapy. However, only case studies have been reported, and a large number of RB cases are needed to define the clinical utility of these and other molecular markers. Both reports dealt with the study of MRD in patients with metastatic disease who underwent intensive treatment. However, this condition is very uncommon in our setting. Molecular markers of disseminated disease may be useful for detecting MDD at diagnosis in patients with histopathological risk factors for extraocular relapse, and could aid the clinician in prescribing adjuvant therapy in these cases, which are common in developing countries such as Argentina.

After optimizing our nested RT-PCR assay, we achieved a final sensitivity for GD2 synthase mRNA detection of at least $200 \mathrm{pg}$ of total RNA in the first round of amplification, and $40 \mathrm{pg}$ in the second. In comparison with the aforementioned study on PGP9.5, IRBP and rod $\beta$-PDE RT-PCR detection, we obtained a much better sensitivity starting from an amount of RNA template three orders scarcer. Thus, our optimization is a very good option for MDD detection in RB, and should encourage others to continue this type of practice in $\mathrm{RB}$ or other malignancies.

The sensitivity achieved allowed us to detect malignant RB cells in a particular PB sample through GD2 synthase mRNA amplification, a task that is often difficult as malignant cells circulate at low concentrations (36). The sample corresponded to a patient who had a tumor at the resection margin of the optic nerve after enucleation. No prognostic implications were drawn from this case since only samples from our tumor bank were used and there was no prospective follow-up. Furthermore, all blood samples from healthy volunteers were negative for GD2 synthase, indicating that this mRNA may be a valuable molecular marker for MDD.

Molecular analysis is difficult in biological compartments such as CSF due to its low cellularity, but is potentially important since CSF is the most common site of the recurrence of metastatic retinoblastoma. Tumor-specific RT-PCR assays have been widely used for the detection of MDD in several biological compartments, but this is the first time that RT-PCR and GD2 synthase were successfully used to identify the presence of tumor cells in CSF in a patient with metastatic $\mathrm{RB}$ in bone marrow. While the use of GD2 synthase as a marker for meningeal infiltration has been previously reported in neuroblastoma (37), to our knowledge it has never been described in RB.

The number of patients studied was an intrinsic limitation of our study and others. Thus, though suggestive, our data are insufficient to reliably demonstrate that the amplification of GD2 synthase mRNA is a valuable molecular marker for MDD in $\mathrm{RB}$. This marker is currently being prospectively evaluated in a larger cohort to confirm its usefulness. Moreover, the sensitivity and the prognostic value of PCR-based assays for the detection of occult tumor cells can be improved by serial sampling and the use of multiple markers.

The ideal MDD marker is tumor specific; it should not be expressed in normal compartments such as bone marrow or PB. However, the potential molecular marker that we 
investigated in this report has been found to be expressed in normal tissues. Indeed, recent publications confirm this fact and propose the utilization of other molecular markers instead $(38,39)$. Quantitative RT-PCR (qRT-PCR) is an indispensable tool for the determination of the threshold between normal and abnormal expression of any type of marker. Certainly, the development of real-time qRT-PCR is valuable for monitoring cancer progression (40), and is currently being carried out at our laboratory for this particular molecular marker. Despite the ubiquitous character of the enzyme, its expression level is low and, to be detected, it requires a system with very high sensitivity. Again, qRT-PCR will prove useful in determining a threshold at which levels of GD2 synthase expression become clearly abnormal.

\section{Acknowledgements}

We would like to thank to Dr Nai-Kong V. Cheung from the Memorial Sloan-Kettering Cancer Center (NY, USA) for kindly providing the anti-GD2 antibody 3F8. M.R. Gabri and D.F. Alonso are members of CONICET. This work was supported by grants PID 0343/03 and PICT 2007/0078 from ANPCYT (Argentina). Support from the Natalí Dafne Flexer Foundation (Argentina), the Fund for Ophthalmic Knowledge (NY, USA), and Elea Laboratories (Argentina) was also received.

\section{References}

1. Abramson DH, Dunkel IJ and Mc Cormick B: Neoplasms of the eye. In: Cancer Medicine. Holland JF and Frei E (eds). BC Decker Inc., Canada, pp1083-1096, 2000.

2. Abramson DH: Retinoblastoma in the 20th century: past success and future challenges, the Weisenfeld lecture. Invest Ophthalmol Vis Sci 46: 2683-2691, 2005.

3. Friend SH, Bernards R, Rogelj S, Weinberg RA, Rapaport JM, Albert DM and Dryja TP: A human DNA segment with properties of the gene that predisposes to retinoblastoma and osteosarcoma. Nature 323: 643-646, 1986.

4. Chantada GL, Dunkel IJ, Qaddoumi I, Antoneli CB, Totah A, Canturk S, Nawaiseh I, Fandiño A, Pífano I, Peksayar G, Ribeiro KB and Abramson DH: Familiar retinoblastoma in developing countries. Pediatr Blood Cancer 53: 338-342, 2009.

5. Chantada GL, Fandiño A, Manzitti J, Urrutia L and Schvartzman E: Late diagnosis of retinoblastoma in a developing country. Arch Dis Child 80: 171-174, 1999.

6. Rodriguez-Galindo C, Wilson M, Chantada GL, et al: Retinoblastoma: one world, one vision. Pediatrics 122: 763-770, 2008.

7. Atchaneeyasakul LO, Wongsiwaroj C, Uiprasertkul M, Sanpakit K, Thephamongkhol K and Trinavarat A: Prognostic factors and treatment outcomes of retinoblastoma in pediatric patients: a single-institution study. Jpn J Ophthalmol 53: 35-39, 2009.

8. Ozdemir H, Tacyildiz N, Unal E, Yavuz G, Ugur H and Gunduz K: Clinical and epidemiological characteristics of retinoblastoma: correlation with prognosis in a Turkish pediatric oncology center. Pediatr Hematol Oncol 24: 221-231, 2007.

9. Naseripour M, Nazari H, Bakhtiari P, Modarres-Zadeh M, Vosough P and Ausari M: Retinoblastoma in Iran: outcomes in terms of patients' survival and global survival. Br J Ophthalmol 93: 28-32, 2009.

10. Chantada GL, Dunkel IJ, de Davila MTG and Abramson DH: Retinoblastoma patients with high risk ocular pathological features: who needs adjuvant therapy? $\mathrm{Br} \mathrm{J}$ Ophthalmol 88: 1069-1073, 2004.

11. Cuenca A, Giron F, Castro D, Fandiño A, Guitter M, de Dávila MTG and Chantada GL: Microscopic scleral invasion in retinoblastoma: clinicopathological features and outcome. Arch Ophthalmol 127: 1006-1010, 2009.
12. Chantada GL, Fandiño A, de Dávila MTG, Manzitti J, Raslawski E, Casak S and Schvartzman E: Results of a prospective study for the treatment of retinoblastoma. Cancer 100: 834-842, 2004.

13. Chantada GL, Fandiño A, Casak S, Manzitti J, Raslawski E and Schvartzman E: Treatment of overt extraocular retinoblastoma. Med Pediatr Oncol 40: 158-161, 2003.

14. Honavar SG, Singh AD, Shields CL, Meadows AT, Demirci H, Cater J and Shields JA: Postenucleation adjuvant therapy in high-risk retinoblastoma. Arch Ophthalmol 120: 923-931, 2002.

15. Gündüz K, Müftüoglu O, Günalp I, Unal E and Taçyildiz N: Metastatic retinoblastoma clinical features, treatment and prognosis. Ophthalmology 113: 1558-1566, 2006.

16. MacKay CJ, Abramson DH and Ellsworth RM: Metastatic patterns of retinoblastoma. Arch Ophthalmol 102: 391-396, 1984.

17. Smith B, Selby P, Southgate J, Pittman K, Bradley C and Blair GE: Detection of melanoma cells in peripheral blood by means of reverse transcriptase and polymerase chain reaction. Lancet 338: 1227-1229, 1991.

18. Mocellin S, Keilholz U, Rossi CR and Nitti D: Circulating tumor cells: the 'leukemic phase' of solid cancers. Trend Mol Med 12: 1130-1139, 2006.

19. Hoon DS, Kuo CT, Wen S, Wang H, Metelitsa L, Reynolds CP and Seeger RC: Ganglioside GM2/GD2 synthetase mRNA is a marker for detection of infrequent neuroblastoma cells in bone marrow. Am J Pathol 159: 493-500, 2001.

20. Lloyd KO and Furukawa K: Biosynthesis and functions of gangliosides: recent advances. Glycoconj J 15: 627-636, 1998.

21. Ruan S, Raj BK and Lloyd KO: Relationship of glycosyltransferases and mRNA levels to ganglioside expression in neuroblastoma cells and melanoma cells. J Neurochem 72: 514-521, 1999.

22. Cheresh DA, Pierschbacher MD, Herzig MA and Mujoo K: Disialogangliosides GD2 and GD3 are involved in the attachment of human melanoma and neuroblastoma cells to extracellular matrix proteins. J Cell Biol 102: 688-696, 1986.

23. Yates AJ, Thompson DK, Boesel CP, Albrightson $\mathrm{C}$ and Hart RW: Lipid composition of human neural tumors. J Lipid Res 20: 428-436, 1979.

24. Cheung IY, Lo Piccolo MS, Kushner BH, Kramer $\mathrm{K}$ and Cheung NK: Quantitation of GD2 synthase mRNA by real-time reverse transcriptase polymerase chain reaction: clinical utility in evaluating adjuvant therapy in neuroblastoma. J Clin Oncol 21: 1087-1093, 2003

25. Furukawa K, Soejima H, Niikawa N and Shiku H: Genomic organization and chromosomal assignment of the human beta1, 4-N-acetylgalactosaminyltransferase gene. Identification of multiple transcription units. J Biol Chem 271: 20836-20844, 1996.

26. Portoukalian J, David MJ, Gain P and Richard M: Shedding of GD2 gangliosides in patients with retinoblastoma. Int J Cancer 53: 948-951, 1993.

27. Chantada GL, Rossi J, Casco F, Fandiño A, Scopinaro M, de Dávila MTG and Abramson DH: An aggressive bone marrow evaluation including immunocytology with GD2 for advanced retinoblastoma. J Pediatr Hematol Oncol 28: 369-373, 2006.

28. Albini A, Melchiori A, Garofalo A, Noonan DM, Basolo F, Taraboletti G, Chader GJ and Gavazzi R: Matrigel promotes retinoblastoma cell growth in vitro and in vivo. Int J Cancer 52: 234-240, 1992.

29. Chomczynski P and Sacchi N: Single-step method of RNA isolation by acid guanidinium thiocyanate-phenol-chloroform extraction. Anal Biochem 162: 156-159, 1987.

30. Chantada GL, Doz F, Antoneli CBG, Grundy R, Stannard FFC, Onc R, Dunkel IJ, Grabowski E, Leal-Leal C, RodríguezGalindo C, Schvartzman E, Beck-Popovic M, Kremens B, Meadows AT and Zucker JM: A proposal for an International Retinoblastoma Staging System. Pediatr Blood Cancer 47: 801-805, 2006

31. Chantada GL, Guitter MR, Fandiño A, Raslawski EC, de Davila MTG, Vaiani E and Scopinaro MJ: Treatment results in patients with retinoblastoma and invasion to the cut end of the optic nerve. Pediatr Blood Cancer 52: 218-222, 2009.

32. Zubizarreta $\mathrm{P}$ and Chantada GL: Circulating retinoblastoma cells in a patient with metastatic disease. Ophthalmic Genet 20: 189-191, 1999.

33. Yamane S, Shirai C, Arimoto A, Komura E, Ohmisono Y, Sawada $\mathrm{T}$ and Matsumura T: Disseminated retinoblastoma successfully treated with myeloablative chemotherapy - implication for molecular detection of minimal residual disease. Bone Marrow Transpl 23: 971-974, 1999. 
34. Gilbert J, Norris MD, Marshall GM and Haber M: Low specificity of PGP9.5 expression for detection of micrometastatic neuroblastoma. Br J Cancer 75: 1779-1781, 1997.

35. Yamashita N, Nishiuchi R, Oda M, Tomiyama Y, Eguchi N, Endo C, Manki A and Seino Y: Molecular detection of metastatic retinoblastoma cells by reverse transcription polymerase reaction for interphotoreceptor retinoid-binding protein mRNA. Cancer 91: 1568-1573, 2001.

36. Szenajch J, Jasiński B, Synowiec A, Kulik J, Chomicka M, Struzyna J, Nowecki Z, Rutkowski P, Ruka W, Kupść W, Siedlecki JA and Wiktor-Jedrzejczak W: Prognostic value of multiple reverse transcription-PCR tyrosinase testing for circulating neoplastic cells in malignant melanoma. Clin Chem 49: 1450-1457, 2003.

37. Rosanda C, Gambini C, Carlini B, Conte M, Bernardi B, Garaventa A and Corrias MV: Diagnostic identification of malignant cells in the cerebrospinal fluid by tumor-specific qRT-PCR. Clin Exp Metastasis 23: 223-226, 2006.
38. Martinez C, Hofmann TJ, Marino R, Dominici $M$ and Horwitz EM: Human bone marrow mesenchymal stromal cells express the neural ganglioside GD2: a novel surface marker for the identification of MSCs. Blood 109: 4245-4248, 2007.

39. Stutterheim J, Gerritsen A, Zappeij-Kannegieter L, Kleijn I, Dee R, Hooft L, van Noesel MM, Bierings M, Berthold F, Versteeg R, Caron HN, van der Schoot $\mathrm{CE}$ and Tytgat GA: PHOX2B is a novel and specific marker for minimal residual disease testing in neuroblastoma. J Clin Oncol 26: 5443-5449, 2008.

40. Wong IH: The sporadic nature of shedding cells in blood: multiple RNA diagnostic testing and prognostication of cancer progression. Clin Chem 49: 1429-1431, 2003. 